\title{
SPERM TRANSFER IN THE JAPANESE QUEENLESS ANT DIACAMMA SP. (HYMENOPTERA: FORMICIDAE)
}

\author{
by
}

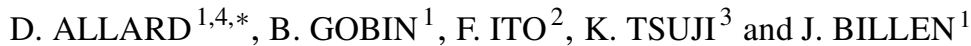 \\ ( ${ }^{1}$ Zoological Institute, University of Leuven, Naamsestraat 59, 3000 Leuven, Belgium; \\ ${ }^{2}$ Faculty of Agriculture, Kagawa University, Ikenobe, Miki 761-0795, Japan; ${ }^{3}$ Faculty of \\ Agriculture, University of the Ryukyus, Okinawa 903-0213, Japan; ${ }^{4}$ Research Assistant \\ of the Fund of Scientific Research - Flanders)
}

\begin{abstract}
Sperm transfer in the Japanese ponerine ant Diacamma sp. was studied by making histological sections through copulating pairs. Males of this species remain attached to the female by their genitalia for several hours, during which they are killed by the gamergate and her nestmates. Our sections revealed that males clasp the female's last sternite with two chelate appendices of the male copulatory organ, called volsellae. We also found that the male inserts his sharp sclerotised penis valves in the female bursa copulatrix, a dorsal evagination of the genital chamber. The penis is inflated inside the female genital chamber, possibly strengthening the connection between the partners. We noticed that the male transfers his sperm to the female in a sheath of gelatinous material, called a spermatophore. Eventually the male's abdomen is removed by the gamergate. Prolonged copulations are viewed as an effective male strategy to ensure unique fatherhood.
\end{abstract}

KEY WORDS: Diacamma sp., prolonged copulation, sperm transfer, spermatophore.

\section{INTRODUCTION}

The mechanism of sperm transfer has been studied quite extensively in several insect orders, but in studies of ant mating systems it has received little attention. Ant queens typically acquire a lifetime supply of sperm (from one or several males) in a single mating episode at the beginning of their life, and store it in their spermatheca. Most studies report the copulatory behaviour and the number of sperm transferred between partners (PETERSEN \& BUSCHINGER, 1971; KELlER \& PASSERA, 1992; HEINZE, 1997). As far as we know, the only record of the mechanism of sperm transfer in ants deals with the myrmicine Carebara vidua studied by ROBERTSON (1995). After a short dispersal flight, winged females of this species attract males with pheromones. Copulation lasts

\footnotetext{
* Corresponding author; e-mail: Diane.Allard@bio.kuleuvenac.be
} 
for about $4 \mathrm{~min}$, and females have been reported to mate with up to four males. During copulation, the male inserts his aedeagus into the bursa copulatrix of the female with the volsellae holding the ventral edge of her terminal gastral tergite. These volsellae are two pincerlike appendages of the male copulatory organ, terminating in an outer rigid cuspis and an inner articulated digitus. Sperm is transferred in a spermatophore, formed by accessory gland secretions (ROBERTSON, 1995). With regard to other Hymenopterans, sperm transfer has been thoroughly studied in several species of Apis (KoENIGER \& KoENIGER, 1991). Sperm is transferred directly from the male seminal vesicles into the female oviduct or spermatheca, without formation of a spermatophore. During the copulation in free flight, males remain attached to the female by their endophallus, and in some species this connection is strengthened by special adhesive organs on the hindlegs of the drone.

The Japanese queenless ant species Diacamma sp. belongs to the subfamily Ponerinae. This subfamily is characterised by the occurrence of a limited queen-worker-dimorphism and the absence of a queen caste in some genera (PEeTERs \& ITO, 2001), including Diacamma (PEETERS, 1991). D. sp. from Japan is the only Diacamma species found in the Central and Southern Ryukyu Islands. It was previously referred to as $D$. rugosum (Le Guillou) by FUKUMOTO et al. (1989) but is, in an ongoing revision, considered to be $D$. indicum (PEETERS, personal communication). Reproductive tasks are performed by a single gamergate, which is a mated worker laying fertilised eggs (PEETERs \& CREWE, 1984). Every worker ecloses with a pair of tiny bladderlike appendages of the mesothorax, called gemmae (PEETERS \& BILLEN, 1991). Reproductive division of labour in several Diacamma species is regulated by mutilation of these gemmae (FuKumoto et al., 1989; PEETERS \& HigASHi, 1989; SoMMER et al., 1993). Shortly after eclosion, the gemmae are aggressively removed by the gamergate (which is the only individual in the colony that retains her gemmae) and her nestmates. This mutilation affects the behaviour and reproductive capacities of the callow. Mutilated workers have never been observed to mate and oviposition is rare in the presence of a gamergate (KIKUTA \& TSUJI, 1999).

Colonies multiply by fission, a process which frequently occurs when the ants move from one nest-site to another (FUKUMOTO \& ABE, 1983). If a colony loses its gamergate, a newly eclosed worker retains her gemmae, mates with a male and becomes the new gamergate. The mating sequence of D. rugosum has been described by FUKUMOTO et al. (1989) and NAKATA et al. (1998) and corresponds to the female calling syndrome (HÖLldOBLER \& BARTZ, 1985). Males leave the parental nest in the early evening 2 days after eclosion, actively flying around in search for 
non-mutilated females. These young females leave the nest at the age of 10 days, in the evening, and attract foreign males by releasing a sex pheromone from the metatibial gland (NAKATA et al., 1998). Males and females mate only once, in a prolonged copulation that can last for 20$24 \mathrm{~h}$. Shortly after the beginning of copulation, the female returns inside the nest with the male attached to her abdomen by his genitalia. After a while the female starts biting the male, and her nestmates sever his wings, legs and head, resulting in his death. Even so the male abdomen remains attached to the female for several hours, until it is finally detached by the female.

Our first aim was to determine how the male achieves this strong connection, by making histological sections through copulating pairs. Secondly, we wanted to investigate the exact mode of sperm transfer using these same histological sections and additional material from recently inseminated females. In this study we follow the nomenclature of the male genitalia given in MICHENER (1956).

\section{MATERIALS AND METHODS}

Eight colonies of Diacamma sp. were excavated on Okinawa Island and kept in the laboratory in artificial nests consisting of a plaster foraging arena $(20 \times 20 \mathrm{~cm})$ with a small sunken nest chamber $(5 \times 15 \times 0.5 \mathrm{~cm})$ covered by a glass plate. The nests were kept at a constant temperature $\left(25^{\circ} \mathrm{C}\right)$ and constant relative humidity $(75 \%)$, and were exposed to a regular day/night cycle $(12 \mathrm{~h} / 12 \mathrm{~h})$. The ants were fed with mealworms and small crickets every other day.

To obtain copulating pairs we reared new females with gemmae in experimental groups. We transferred sets of five mutilated workers and three pupae from mother-colonies into new nest-boxes $(10 \times 10 \mathrm{~cm})$. Since no gamergate is present, the first eclosing callow will retain its gemmae. When the callow in a group was 10 days old, males were added. The males were taken from the foraging arena of the colonies without a gamergate, which exclusively produce male offspring. Males that have left the nest chamber in search of a female are most likely to be ready for mating. The groups were then checked several times a day for copulating pairs. We used some virgin males to study the male external genitalia.

For histological study, individuals were killed by placing them in the freezer for a few minutes. The ants were dissected in Ringer-Jolly solution. The gasters were fixed in glutaraldehyde, post-fixed in osmiumtetroxide, dehydrated in acetone, embedded in araldit and sectioned using a Reichert Ultracut E microtome. We stained the semithin sections 
$(1 \mu \mathrm{m})$ with a methylene-blue/thionin solution. Thin sections $(70 \mathrm{~nm})$ for transmission electron microscopy were contrasted with uranyl acetate and lead citrate and viewed in a Zeiss EM 900 electron microscope.

We observed six copulations in the laboratory. Three mating pairs were killed in copula by placing them in the freezer. In two of these, male and female were separated during dissection to examine the male genitalia. Two other females died 2 days after copulation and were unsuitable for microscopic study. The sixth female was dissected 6 days after copulation.

\section{RESULTS}

Longitudinal sections through the abdomen of the copulating pair show how the male inserts his aedeagus into the female genital tract (fig. 1). The male is positioned with his dorsal side downwards during copulation. The aedeagus consists of two sharp sclerotised penis valves enclosing the less sclerotised penis. The valves are inserted in the female bursa copulatrix, partially opening and extending it (fig. 1). The bursa is a dorsal evagination of the female genital tract lined with a very thick cuticle, rendering it a strong yet elastic structure. The penis, a transparent, crumpled structure in non-copulating males, is expanded inside the oviduct (fig. 1, 6 ). We also noticed that the male grasps the female's last sternite between its volsellar digitus and cuspis (fig. 3).

The sperm itself is transferred inside a spermatophore. We observed a spermatophore in each of the three females dissected during copulation. This bean-shaped mass of accessory gland secretion is injected into the oviduct through the male gonopore, which is situated between the two penis valves at the base of the aedeagus. A strand of secretion is visible extending from the spermatophore to the male gonopore (fig. 1). The spermatophore is approximately $1 \mathrm{~mm}$ long and $0.5 \mathrm{~mm}$ in diameter $(n=2)$ and adapts to the general shape of the oviduct. In the oviduct of one specimen, we observed small particles around the top of the spermatophore, which with electron microscopy, were confirmed to be free spermatozoa. These loose sperm cells could be an artifact due to the preparation methods. The sperm mass is enclosed in mucus at the top of the spermatophore (fig. 4). This package is positioned near the opening of the spermathecal duct in the oviduct (fig. 5), from where the sperm is transferred to the spermatheca. Figure 5 shows a strand of material from the spermatophore penetrating inside the spermathecal duct.

In the individual dissected 6 days after copulation, histological sections through the spermatheca showed that it contained sperm. We found no remains of a spermatophore in the oviduct. 

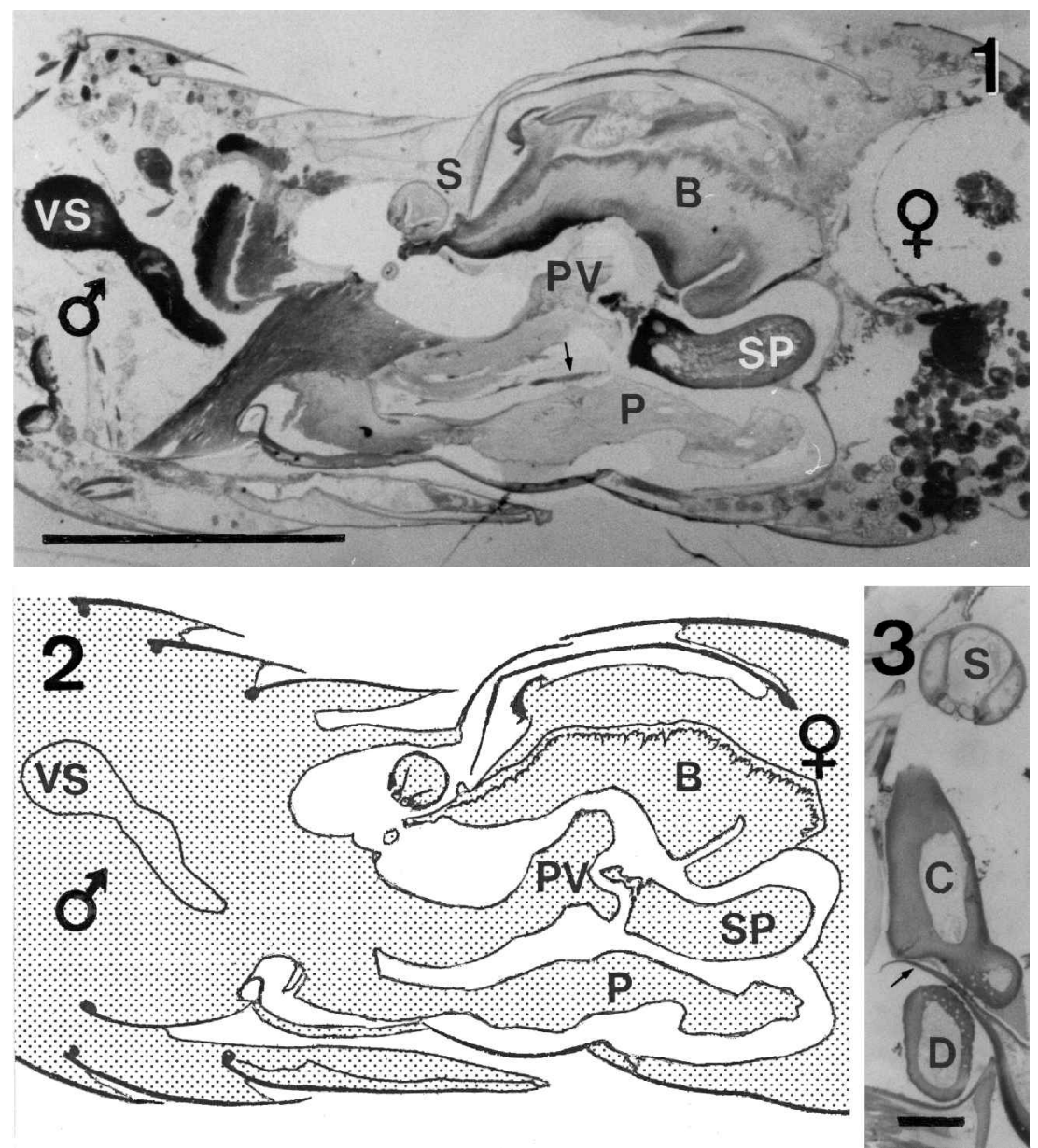

Fig. 1. Longitudinal section through copulating pair of Diacamma sp. showing male aedeagus inserted inside female genital tract, and spermatophore (SP) inside oviduct. Arrow points at strand connecting spermatophore to male gonopore. Note cross section of sting $(\mathrm{S})$, which is directed sideways by female during copulation. Scale bar: $1 \mathrm{~mm}$.

Fig. 2. Schematical representation of fig. 1 .

Fig. 3. Detail showing volsellar digitus (D) and cuspis (C) of male clasping the last sternite of female (arrow) during copulation. Scale bar: $100 \mu \mathrm{m}$.

B: bursa copulatrix; C: cuspis; D: digitus; P: inflated penis; PV: penis valves; S: sting; SP: spermatophore; VS: vesicula seminalis.

Precise measurements of the total duration of the copulations could not be made because we missed either the start or the end of it. Nevertheless, 

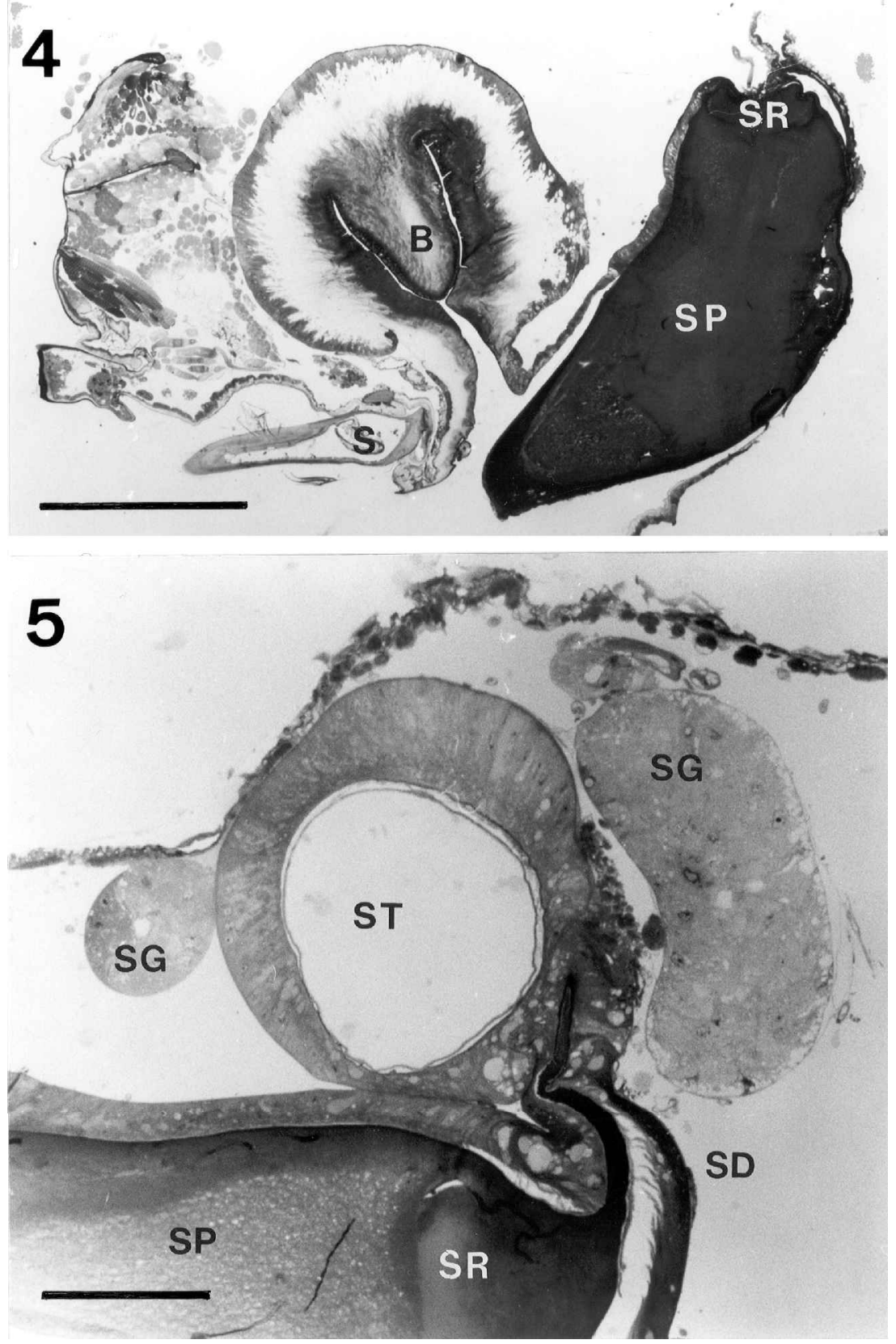
from incomplete video recordings, we estimated the minimum duration to be $7.5 \mathrm{~h}$.

\section{DISCUSSION}

In Diacamma sp. the sperm is transferred to the female in a spermatophore, produced by the male accessory glands. It is injected into the female genital tract, with the ventrally situated inflated penis apparently functioning as a conducting gutter. The transfer of sperm in a spermatophore is a common phenomenon in various insect orders (TUZET, 1977; CHOE \& CRESPI, 1997). The present study is the second reporting the production of spermatophores in the Formicidae. Insect spermatophores have been developed as an adaptation to dry environments at the colonisation of terrestrial habitats. They were originally placed on a substrate by the male and subsequently taken up by the female. Further in the evolution, the transfer of these spermatophores has become more direct through an increased contact between the partners. This provides a greater insurance for reproductive success of the male. A next step in the evolution of indirect to direct insemination is the disappearance of spermatophores (TUZET, 1977).

In several Orthoptera (GWYNNE, 1997) and Lepidoptera (RUTOWSKI, 1997), spermatophores contain nutrients that are taken up by the female, thereby representing a form of parental investment by the males. Complementary research is needed to assess possible functions and consequences of the production of spermatophores in Formicidae and in Hymenoptera in general.

The spermatophores of Carebara vidua (ROBERTSON, 1995) do not quite resemble the ones we found in Diacamma sp. In the latter the sperm mass represents a much smaller part of the whole structure. This factor might be influenced by the timing of the sperm transfer and the exact moment when we interrupted it. Copulation in $C$. vidua lasts only 4 min, whereas it can continue for several hours in $D$. sp. Nevertheless, spermathecal sperm counts could reveal how many spermatozoa are

Fig. 4. Longitudinal section through genital tract of female during copulation, showing spermatophore (SP) inside oviduct. Male genitalia have been removed during dissection. Scale bar: $500 \mu \mathrm{m}$.

Fig. 5. Longitudinal section through genital tract of female during copulation showing material from sperm package (SR) in top of spermatophore (SP) penetrating inside spermathecal duct (SD). Scale bar: $100 \mu \mathrm{m}$.

B: bursa copulatrix; S: sting; SD: spermathecal duct; SG: spermathecal gland; SP: spermatophore; SR: sperm package; ST: spermatheca. 
transferred. Gamergates of Diacamma do not require a large amount of sperm considering their very low egg laying rates and short lifespans (less than 2 years, TSUJI et al., 1996), resulting in small colonies. This contrasts with the thousands of workers and sexuals produced by Carebara queens, requiring a great number of gametes. Experiments concerning the exact timing of sperm transfer in Diacamma, and the number of sperm involved, are in progress.

The male genitalia are responsible for the strong connection between the partners. In Diacamma the male grasps the female's last sternite between its volsellar digitus and cuspis. The sclerotised aedeagus is inserted into the female genital chamber with the penis valves fitting inside the bursa copulatrix. The inflated penis presumably strengthens this connection, functioning as 'a cork in a bottle'. A comparable phenomenon has been observed in Apis mellifera. There the connection between queen and drone during the mating flight is mainly achieved by the endophallus, which is filled with mucus under high muscular pressure in the queen's sting chamber (KoENIGER \& KoENIGER, 1991). It must be noticed, however, that copulation in Apis lasts only a few seconds. In C. vidua, during a copulation that lasts on average $4 \mathrm{~min}$, the male holds the female's last sternite with his volsellae and inserts his aedeagus in the female bursa copulatrix (ROBERTSON, 1995). The use of a combination of different fastening elements in Diacamma presumably accounts for the exceptionally long duration of copulation in this species. In most ant species studied, copulations last only a few minutes (KELLER \& PASSERA, 1992) and are ended by the female biting the male.

Prolonged copulations are viewed as a form of mate guarding, a male strategy to prevent their partners being inseminated by rivals. In social insects, multiple inseminations of the female reduce a male's fitness through a reduction of his genetic contribution to the female's offspring and through detrimental effects on the genetic relatedness among this offspring. Females are expected to favour multiple mating for several reasons, e.g. the acquisition of a large and sufficient sperm supply, the increased genetic diversity of the colony and a lowered relatedness among their offspring. These last two factors are important determinants of colony productivity, resistance to parasites and disease, and play a major role in conflicts on sex ratio and male production (BOOMSMA \& RATNIEKS, 1996). Ant females are receptive during just a short episode at the start of their life, and males can use different tactics to coerce them not to remate, e.g. blocking the female reproductive tract, rendering the female unattractive to other males, or damaging tactics such as the use of seminal toxins (JOHNSTONE \& KELLER, 2000). In the queenless ponerine Dinoponera quadriceps, the genitalia of the male remain attached to the 


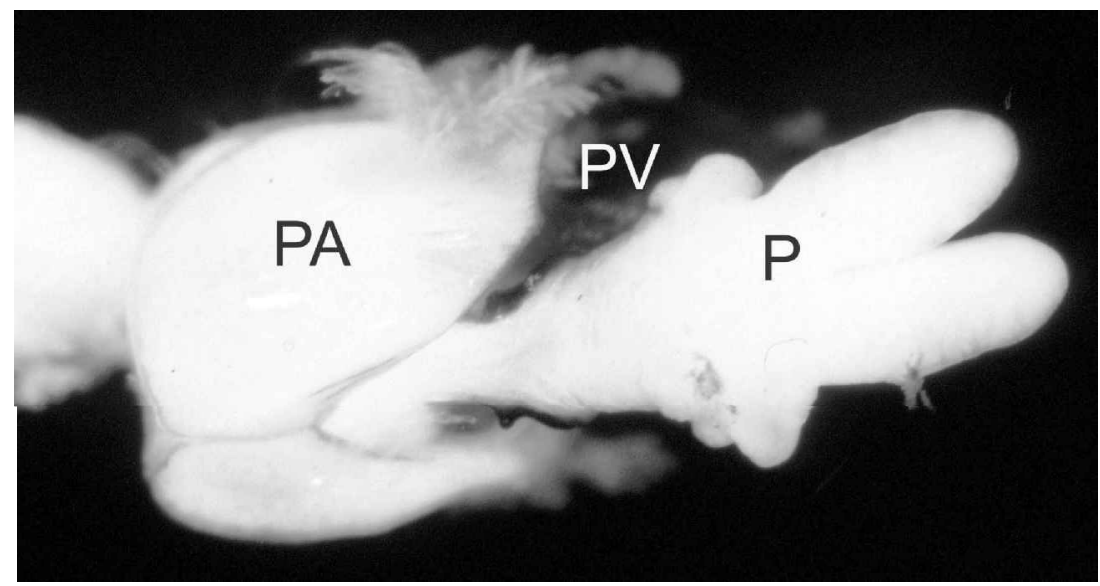

Fig. 6. Photograph of the male genitalia as they appear during copulation. The female was removed to show the bilobed inflated penis. P: inflated penis; PA: paramere; PV: penis valve.

female's abdomen for 30 min, forming a mating plug and blocking the access to potential rivals (MONNIN \& PEETERS, 1998). The abdomen of Diacamma sp. males likely serves the same function as it blocks the female genital tract for several hours. Additional observations of Diacamma, preferably in the field, are needed to assess if other males interfere with the copulating pair around or inside the nest.

\section{ACKNOWLEDGEMENTS}

We are grateful to Koen Collart for his expertise and time in producing the histological sections.

\section{REFERENCES}

Boomsma, J.J. \& F.L. Ratnieks, 1996. Paternity in eusocial Hymenoptera. Phil. Trans. R. Soc. Lond. B 351: 947-975.

Choe, J.C. \& B.J. Crespi, 1997. The Evolution of Mating Systems in Insects and Arachnids. Cambridge University Press, Cambridge.

Fuкumoto, Y. \& T. AвE, 1983. Social organization of colony movement in the tropical Ponerine ant Diacamma rugosum (Le Guillou). J. Ethol. 1: 101-108.

Fukumoto, Y., T. AвE \& A. TAKi, 1989. A novel form of colony organization in the 'queenless' ant Diacamma rugosum. Physiol. Ecol. Japan 26: 55-61.

GWynne, D.T., 1997. The evolution of edible 'sperm sacs' and other forms of courtship feeding in crickets, katydids and their kin (Orthoptera: Ensifera). In: J.C. Choe \& B.J. Crespi (Eds): The Evolution of Mating Systems in Insects and Arachnids: 110129. Cambridge University Press, Cambridge. 
Heinze, J., 1997. Male reproductive strategies in ants. In: V.E. Kipyatkov (Ed.): Proc. Int. Coll. Social Insects, St. Petersburg, 1997: vol. 3-4, 179-187.

Hölldobler, B. \& S.H. BARTZ, 1985. Sociobiology of reproduction in ants. In: B. Hölldobler \& M. Lindauer (Eds): Experimental behavioral ecology: 237-257. G. Fischer Verlag, Stuttgart.

Johnstone, R.A. \& L. Keller, 2000. How males can gain by harming their mates: Sexual conflict, seminal toxins, and the cost of mating. Am. Nat. 156: 368-377.

KELLER, L. \& L. PASSERA, 1992. Mating system, optimal number of matings, and sperm transfer in the Argentine ant Iridomyrmex humilis. Behav. Ecol. Sociobiol. 31: 359366.

KikutA, N. \& K. Tsuji, 1999. Queen and worker policing in the monogynous and monandrous ant, Diacamma sp. Behav. Ecol. Sociobiol. 46: 180-189.

Koeniger, N. \& G. Koeniger, 1991. An evolutionary approach to mating behaviour and drone copulatory organs in Apis. Apidologie 22: 581-590.

MiChener, C.D., 1956. Hymenoptera. In: S.L. Tuxen (Eds): Taxonomist's Glossary of Genitalia in Insects: 131-140. Ejnar Munksgaard, Copenhagen.

Monnin, T. \& C. PeEters, 1998. Monogyny and regulation of worker mating in the queenless ant Dinoponera quadriceps. Anim. Behav. 55: 299-306.

NAKATA, K., K. Tsuji, B. Holldobler \& A. TAKi, 1998. Sexual calling by workers using the metatibial glands in the ant, Diacamma sp., from Japan (Hymenoptera, Formicidae). J. Insect Behav. 11: 869-877.

Peeters, C., 1991. The occurrence of sexual reproduction among ant workers. Biol. J. Linn. Soc. 44: 141-152.

Peeters, C. \& J.P.J. Billen, 1991. A novel exocrine gland inside the thoracic appendages ('gemmae') of the queenless ant Diacamma australe. Experientia 47: 299-231.

PeEters, C. \& R. CRewe, 1984. Insemination controls the reproductive division of labour in a ponerine ant. Naturwissenschaften 71: 50-51.

Peeters, C. \& S. Hig ASHi, 1989. Reproductive dominance controlled by mutilation in the queenless ant Diacamma australe. Naturwissenschaften 76: 177-180.

Peeters, C. \& F. ITO, 2001. Colony dispersal and the evolution of queen morphology in social Hymenoptera. Annu. Rev. Entomol. 46: 601-630.

Petersen, M. \& A. Buschinger, 1971. Das Begattungsverhalten der Pharaoameise, Monomorium pharaonis (L.). Z. ang. Ent. 68: 168-175.

Robertson, H.G., 1995. Sperm transfer in the ant Carebara vidua F. Smith (Hymenoptera, Formicidae). Insectes Soc. 42: 411-418.

RutowsKi, R.L., 1997. Sexual dimorphism, mating systems and ecology in butterflies. In: J.C. Choe \& B.J. Crespi (Eds): The Evolution of Mating Systems in Insects and Arachnids: 257-272. Cambridge University Press, Cambridge.

Sommer, K., B. Hölldobler \& H. Rembold, 1993. Behavioral and physiological aspects of reproductive control in a Diacamma species from Malaysia (Formicidae, Ponerinae). Ethology 94: 162-170.

Tsuji, K., K. NAKATA \& J. Heinze, 1996. Lifespan and reproduction in a queenless ant. Naturwissenschaften 83: 577-578.

Tuzet, O., 1977. Les spermatophores des insectes. In: P. Grassé (Ed.): Traité de Zoologie, Tome VIII, Fascicule V-A: 277-330. Masson, Paris. 